\title{
Poles of Inaccessibility: A Calculation Algorithm for the Remotest Places on Earth
}

\author{
DANIEL GARCIA-CASTELLANOS* \& UMBERTO LOMBARDO** \\ *ICT Jaume Almera, Sole i Sabarís, Barcelona, Spain \\ **Universität Bern, Bern, Switzerland
}

\begin{abstract}
An algorithm is presented to calculate the point on the surface of a sphere maximising the great-circle distance to a given spherical polygon. This is used to calculate the spots furthest from the sea in major land masses, also known as Poles of Inaccessibility (PIA), a concept that has raised the interest of explorers. For the Eurasian pole of inaccessibility (EPIA), the results reveal a misplacement in previous calculations ranging from 156 to $435 \mathrm{~km}$. Although in general there is only one pole for a given coastline, the present calculations show that, within the error inherent to the definition of the coastline, two locations are candidates for EPIA, one equidistant from Gulf of $\mathrm{Ob}$, Gulf of Bengal and Arabian Sea, and the other equidistant from Gulf of Ob, Gulf of Bengal and Gulf of Bohai, both poles being located in the north westernmost Chinese province of Xinjiang. The distance to the sea at these locations is 2510 and $2514 \mathrm{~km}$ respectively, about $120 \mathrm{~km}$ closer than generally thought.
\end{abstract}

KEY WORDS: Distance to sea, computer method

\section{Introduction}

Distance from the sea is historically related to isolation and inaccessibility. A Pole of Inaccessibility (PIA) is defined as the location furthest from a particular coastline (Figure 1). The concept was first introduced by Vilhjalmur Stefansson (1920) to distinguish between the North Pole and the most difficult-to-reach place in the Arctic. Thereafter, it has been widely used to refer to the place in Antarctica furthest from the sea (e.g. Ramseier, 1966; Lambert, 1971; Bonner, 1987). This exploration challenge was first achieved in 1958 by the 2nd Soviet Antarctic Expedition led by Aleksei Treshnikov (Petrov, 1959).

The term is also used to refer to the place on Earth that is furthest from any ocean (Eurasian Pole of Inaccessibility, hereafter referred as EPIA), located in central Asia. Explorers such as Cable \& French (1944, p. 94) refer to the region of the Dsungarei Desert as "the spot of the globe which is farthest removed from any sea or ocean".

Correspondence Address: Daniel Garcia-Castellanos, ICT Jaume Almera, Sole i Sabarís, Barcelona, 08028, Spain. Email: danielgc@ija.csic.es

ISSN 1470-2541 Print/1751-665X Online (C) 2007 Royal Scottish Geographical Society DOI: $10.1080 / 14702540801897809$ 


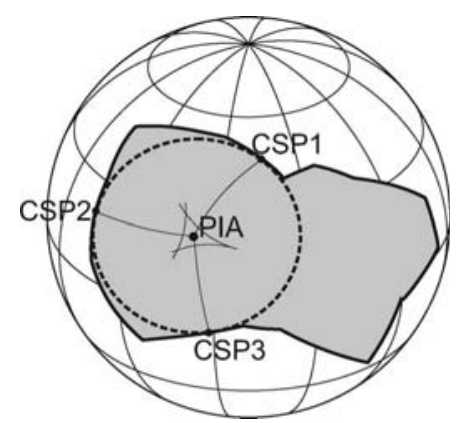

Figure 1. A pole of inaccessibility (PIA) is a point in a continent (in grey) furthest from a given coastline. By definition, a pole of inaccessibility has only three closest shoreline points (CSP)

In recent years, as expeditions have been conducted to document the PIA of Antarctica (19th January 2007) and Eurasia (Crane \& Crane, 1987), there has been an increasing interest in the subject, while academic documentation remains very scarce. Although graphical methods to calculate such poles are long known, as digital coastlines and geographical databases become gradually available, the necessity for a numerical method is growing.

In this paper, a simple method is proposed and used to calculate the PIA's associated to the largest landmasses on Earth. The application of this method reveals an error of between 156 and $435 \mathrm{~km}$ in the location popularly regarded as the EPIA (Crane \& Crane, 1987).

\section{Methodology}

An iterative method is designed to calculate the PIA associated to a given coastline. For each iteration, a successively smaller region $R$ defined by a longitude range $\lambda_{\min }, \lambda_{\max }$ and a latitude range $\phi_{\min }, \phi_{\max }$ is defined centred on a candidate PIA location $\lambda_{P I A}, \phi_{P I A}$. Initially, $R$ corresponds to the region in which the location of maximum distance to the coast is searched. A regular, rectangular grid of $N_{\lambda}$ by $N_{\phi}$ nodes is then defined in $R$. Most results shown in this paper use $N_{\lambda}=N_{\phi}=21$. The distance from each of those 441 nodes to the coastline is then calculated and a new candidate location $\lambda_{P I A}^{\prime}, \phi_{P I A}^{\prime}$ is defined as the node maximising such distance. Subsequently the region $R$ is reduced in size by a factor $\sqrt{2}$ and centred at $\lambda^{\prime}{ }_{P I A}$, $\phi_{\text {PIA }}^{\prime}$ and the procedure is iterated. Because spherical distance is a continuous function of the location $\lambda, \phi$, this algorithm ensures convergence towards a local maximum of the distance to the shore, but it does not ensure that it is the absolute maximum. Mapping the successive results as in Figures 2 to 4 easily allows discriminating whether a relevant local maximum is being missed with the automatic method.

If the polygon is given with high enough resolution (as is the case of the Earth coastline), the distance between a point and the polygon in spherical coordinates is equivalent to the smallest distance from the point to all of the polygon's corners. 


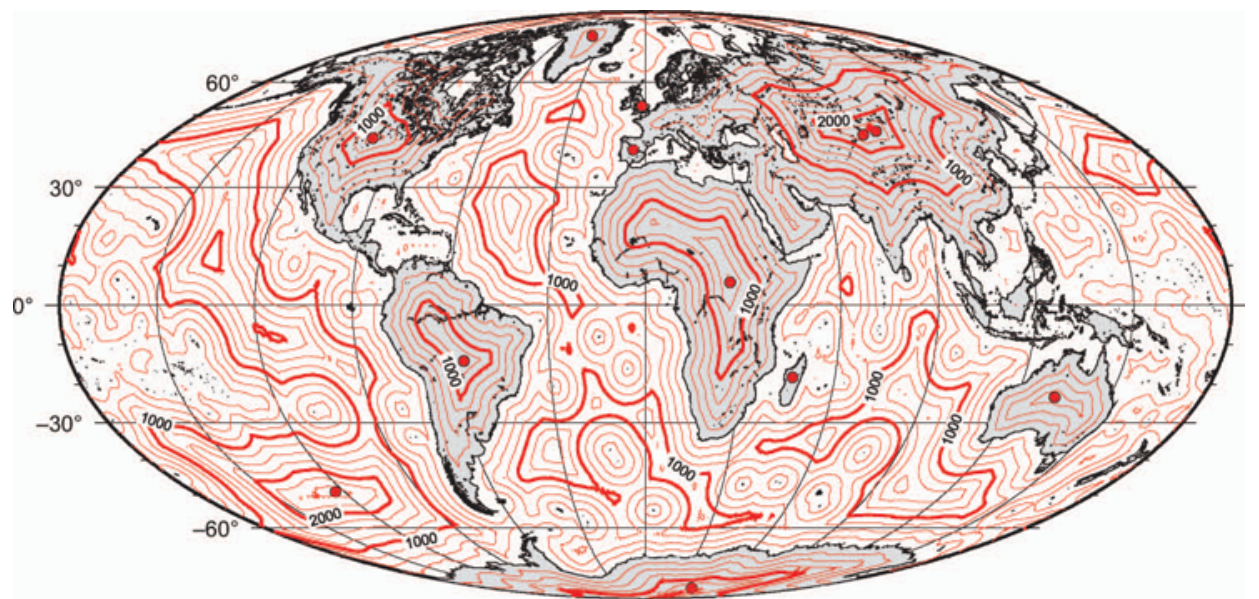

Figure 2. World map of distance to the coastline derived with the method described in this paper. Contours every $250 \mathrm{~km}$. Small circles indicate PIAs listed in Table 1

The great-circle distance $d$ between tw $\equiv$ ints $\left[\lambda_{0}, \phi_{0}\right]$ and $\left[\lambda_{1}, \phi_{1}\right]$ on a spherical Earth can be derived from the sphericaintrgonometry cosine rule:

$$
\mathrm{d}_{x 0, y 0}^{x 1, y 1}=\mathrm{R}_{\mathrm{E}} \cdot \arccos \left(\sin \left(\varphi_{0}\right) * \sin \left(\varphi_{1}\right)+\cos \left(\varphi_{0}\right) * \cos \left(\varphi_{1}\right) * \cos \left(\lambda_{1}-\lambda_{0}\right)\right)
$$

where $R_{E}$ is the mean radius of the Earth, taken as $6372.7 \mathrm{~km}$. By definition, arbitrarily-shaped polygons such as a coastline have one single PIA and 3 equidistant closest shoreline points (CSP) (see Figure 1).

If the vertex distribution in the polygon is not dense enough then the formula corresponding to the distance from a point to a line segment should be used instead. The coastline polygon used in the present work is taken from Wessel \& Smith (1996; in turn based on the World Vector Shoreline), based on WGS-84 ellipsoid and with a resolution of about $500 \mathrm{~m}$. The coastline used here excludes lakes and endorheic seas such as the Caspian Sea. Its arbitrariness in estuaries and deltaic areas (boundary between river and open sea) is often in the order of $10 \mathrm{~km}$.

The computer code to implement the algorithm previously described is written in ANSI C language in combination with C-shell Unix scripts, available at the website http://cuba.ija.csic.es/ danielgc/PIA/. A total of about 80000 geographical coordinates are checked to calculate one PIA with a precision of ca. $1 \mathrm{~km}$, which takes about 110 minutes of computation time of a standard personal computer.

\section{Results}

The first iterations of the algorithm are performed using $N_{\lambda}=N_{\phi}=201$, in order to obtain a detailed world map of distance to the coastline (Figure 2). The results predict correctly that the point furthest from the ocean lies in central Eurasia, equidistant with the Artic Ocean, the Yellow Sea and the Arabian Sea. When zooming in into central Eurasia (Figures 3 and 4), a relative unusual case of two local 


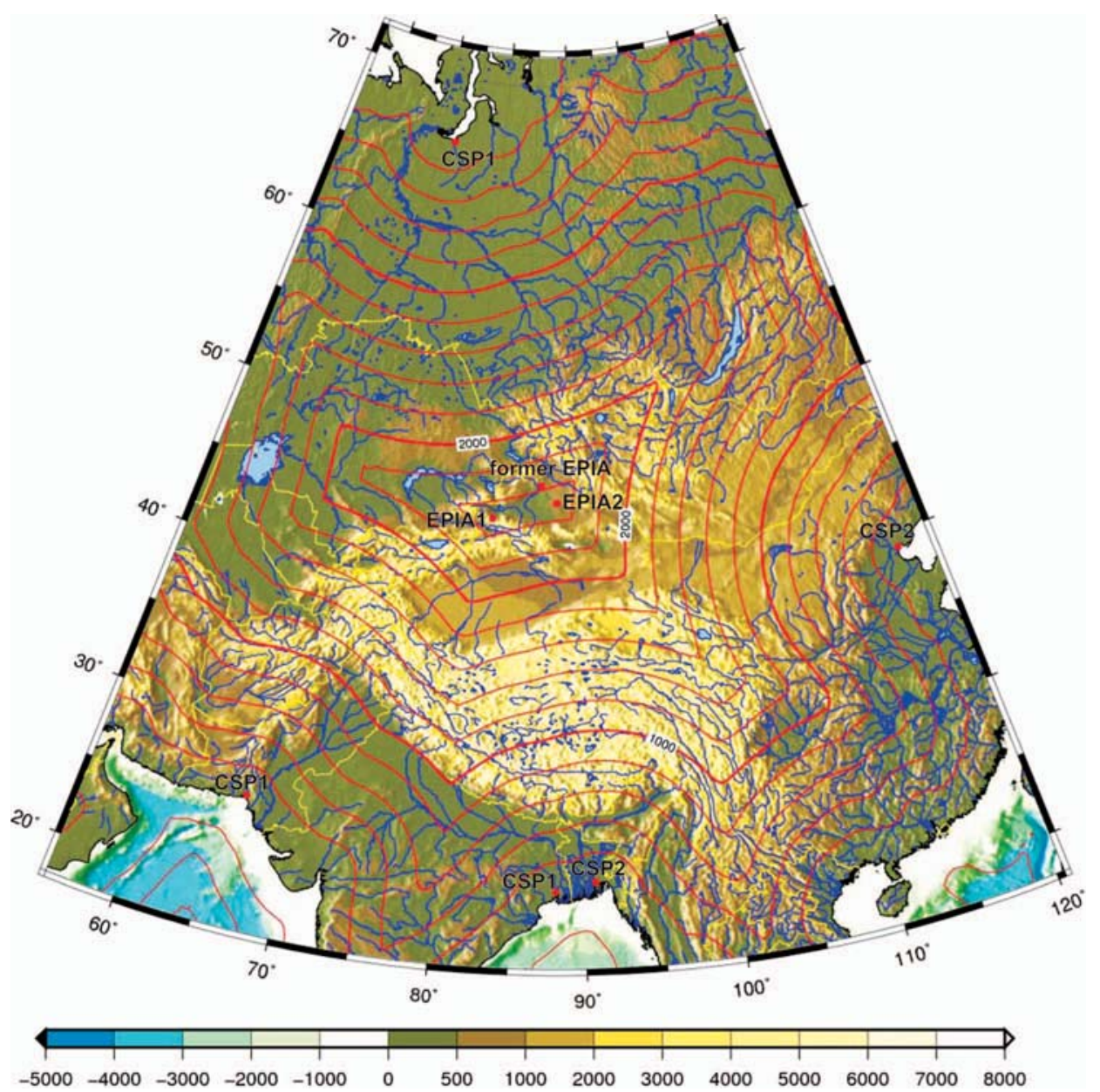

Figure 3. Contour map of distance to the coastline in Asia. Contour lines every $200 \mathrm{~km}$. The location of EPIA1, EPIA2, the previously reported location of EPIA, and the respective closest shoreline points (CSP; see Figure 1) are indicated

maxima with similar peak values becomes apparent. Treating separately both areas, the locations of both EPIA candidate points are obtained (Table 1): EPIA1 is distant $2510 \pm 10 \mathrm{~km}$ far from the sea (CSPs: Gulf of Ob, Gulf of Bengal and Arabian Sea), whereas EPIA2 is $2514 \pm 7 \mathrm{~km}$ far from Gulf of Ob, Gulf of Bengal and Gulf of Bohai. Because the CSPs in the Gulf of Bengal and the Arabian Sea are in deltaic areas, there is an intrinsic uncertainty in defining the coastline (Figure 3). According to the shoreline geometry in those areas, such uncertainty is here taken as 20 and $15 \mathrm{~km}$ respectively, resulting in about half that uncertainty for the pole location (Table 1). Because these uncertainty values are larger than the difference in distance to the ocean between EPIA1 and EPIA2, it follows that both locations are equally plausible. These results can be easily checked using any available GIS software, Google Earth, or similar facilities. 


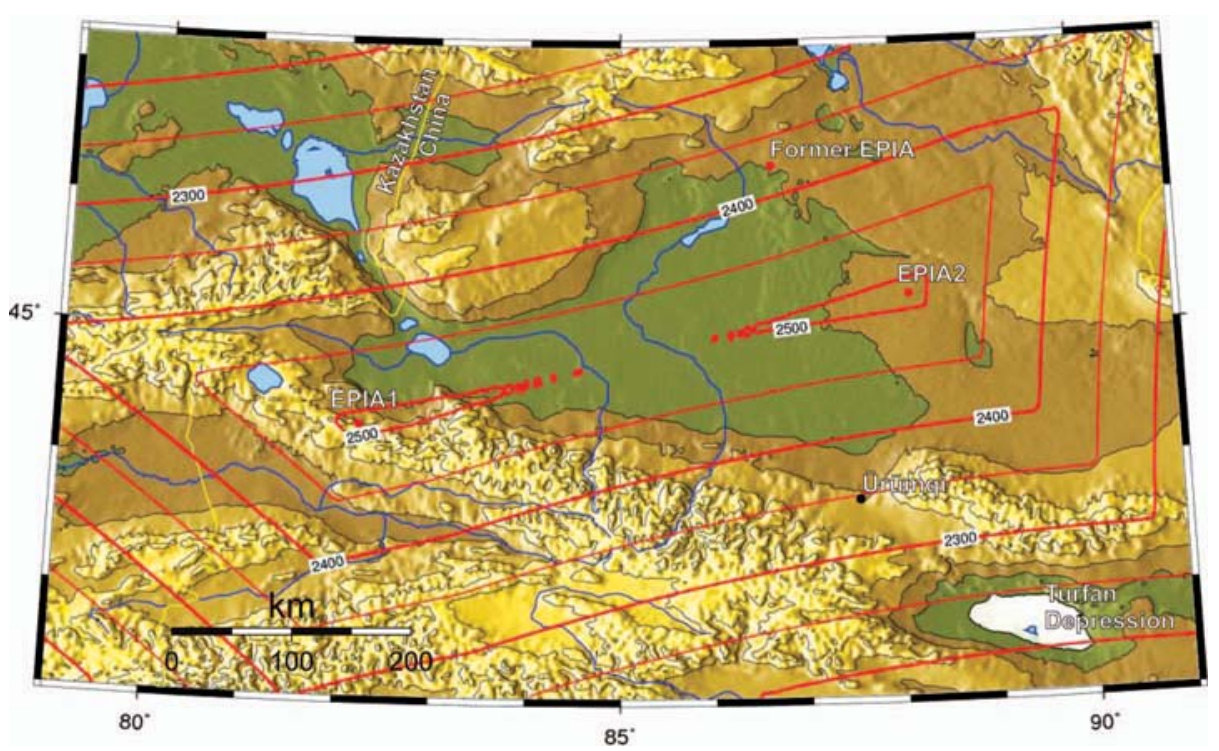

Figure 4. Detailed location map of EPIA1, EPIA2, and a previously reported location of EPIA in Central Asia. Contour lines of distance to the sea every $50 \mathrm{~km}$. Topographic relief is illuminated from the west and contoured at 500, 1000, 2000, 3000 and $4000 \mathrm{~m}$ above sea level. Shade as in Figure 3. The town of Ürümqi is indicated for reference

Table 1. Resulting Poles of Inaccessibility (PIA) for selected continents and other areas. Uncertainty is mostly related to ambiguity in the definition of the coastline at river mouths or glaciers

\begin{tabular}{|c|c|c|c|c|c|}
\hline \multirow[b]{2}{*}{ Region } & \multicolumn{5}{|c|}{ PIA } \\
\hline & $\begin{array}{l}\text { Longitude } \\
\text { (deg. E) }\end{array}$ & $\begin{array}{l}\text { Latitude } \\
\text { (deg. N) }\end{array}$ & $\begin{array}{c}\text { distance } \\
(\mathrm{km})\end{array}$ & $\begin{array}{l}\text { uncertainty } \\
(\mathrm{km})\end{array}$ & $\begin{array}{l}\text { Altitude } \\
(\mathrm{m})\end{array}$ \\
\hline Antarctica $^{a}$ & -82.97 & 54.97 & 1300 & \pm 110 & 3718 \\
\hline Africa & 26.17 & 5.65 & 1814 & \pm 2 & 640 \\
\hline America, North & -101.97 & 43.36 & 1639 & \pm 14 & 1030 \\
\hline America, South & -56.85 & -14.05 & 1517 & \pm 12 & 396 \\
\hline Australia & 132.27 & -23.17 & 928 & \pm 6 & 600 \\
\hline \multicolumn{6}{|l|}{ Eurasia } \\
\hline EPIA1 & 82.19 & 44.29 & 2510 & \pm 10 & 2700 \\
\hline EPIA2 & 88.14 & 45.28 & 2514 & \pm 7 & 710 \\
\hline former EPIA ${ }^{b}$ & 86.67 & 46.28 & 2645 & ? & 510 \\
\hline Great Britain & -1.56 & 52.65 & 108 & \pm 8 & 100 \\
\hline Greenland & -41.00 & 76.50 & 469 & \pm 25 & 2520 \\
\hline Iberian Peninsula & -4.51 & 39.99 & 362 & \pm 4 & 595 \\
\hline Madagascar & 46.67 & -18.33 & 260 & \pm 1 & 1220 \\
\hline Pacific (Point Nemo) & -123.45 & -48.89 & 2690 & \pm 3 & 0 \\
\hline
\end{tabular}

Notes: ${ }^{a}$ Coordinates of the soviet station. Not calculated in this work. ${ }^{\mathrm{b}}$ Commonly accepted, undocumented calculation.

The same technique is applied to other landmasses as well as to calculate the location of maximum distance to the coast in the Pacific Ocean, with the resulting PIA locations listed in Table 1. Only the PIA of Greenland and Antarctica show 


\section{D. Garcia-Castellanos \& U. Lombardo}

uncertainties larger than that found for EPIA, due to the presence of glaciers along their coasts. The location of the PIA of Great Britain is affected by uncertainty on the eastern termination of Weston Bay, where a limit between river and sea is difficult to define. This similarly occurs for South America, North America, and Australia. The PIA's of Africa (easternmost Central African Republic) and Iberia (80 km SW from Madrid) are better determined (errors lesser than $4 \mathrm{~km}$ ) because none of the respective CSP's coincide with estuaries.

\section{Discussion on the Eurasian Pole of Inaccessibility}

Previous (undocumented) calculations of the EPIA did not account for the Gulf of $\mathrm{Ob}$ as part of the seas, yielding the location $46^{\circ} 16.8^{\prime} \mathrm{N} 86^{\circ} 40.2^{\prime} \mathrm{E}$ (see Figure 4; this location is equidistant $2648 \mathrm{~km}$ to the Gulf of Baydaratskaya in the Arctic Ocean, the Gulf of Bengal, and the Gulf of Bohai in East China). However, there is no basis to exclude the Gulf of $\mathrm{Ob}$ as part of the open sea waters, and all available cartography displays the $10-12 \mathrm{~m}$ deep and up to $80 \mathrm{~km}$-wide Gulf of $\mathrm{Ob}$ as part of the ocean. Accounting for the Gulf of $\mathrm{Ob}$ as part of the Seas implies a large shift of the EPIA which has two solutions within the uncertainty related to the definition of coastline, as shown in the previous section.

The two candidate poles found in this paper reduce the Earth's maximum distance to the coast by more than $130 \mathrm{~km}$, and modify the location of the PIA by $435 \mathrm{~km}$ (EPIA1) and $156 \mathrm{~km}$ (EPIA2) relative to previous calculations. In the case of EPIA1, also one of the CSP changes from the Gulf of Bohai (East China) to the Arabian Sea. These results question the only documented attempt to explore the EPIA by two explorers in 1986 (Crane \& Crane, 1987).

EPIA1 lies near Kokirqin Shan Mountain (3698 m), at an area of high relief and difficult access at $>2000 \mathrm{~m}$ above sea level, close to the Chinese borders with Kazakhstan and Kyrgyzstan. EPIA2 lies at $710 \mathrm{~m}$ altitude, $174 \mathrm{~km}$ NNE of Ürümqi.

Besides being far from the oceans, both poles are in the largest endorheic basin in the world, meaning there is no fluvial connection to the sea (Cable \& French, 1944). This is partially the result of low precipitation values of $200-350 \mathrm{~mm} / \mathrm{yr}$ as a result of continentality. Both factors have probably enhanced the historical isolation of this region acting as a natural border between the Chinese and the Western civilisations. Its faint presence in history is mostly linked to the relative vicinity (a few hundred $\mathrm{km}$ ) of the ancient Silk Road. Unsurprisingly, the region is among the less populated areas of the world, and the ethnic group longest rooted in the region, the Uyghur, is linguistically included in the Turkic family and interlinks with the population speaking Chinese languages.

\section{Conclusions}

The location on Earth furthest from the ocean is located in the north-western Chinese province of Xinjiang. Within the uncertainty inherent to the definition of the $\operatorname{coas} \equiv$ two locations are proposed as Pole of Inaccessibility: EPIA1 $\left(44^{\circ} 18^{\prime} 1^{\prime \prime} \mathrm{N}\right.$; $\left.81^{\circ} 51^{3} 31^{\prime \prime} \mathrm{E}\right)$ and EPIA2 $\left(45^{\circ} 17^{\prime} 60^{\prime \prime} \mathrm{N} ; 88^{\circ} 8^{\prime} 24^{\prime \prime} \mathrm{E}\right)$. EPIA1 is equidistant $2510 \pm 10 \mathrm{~km}$ from Gulf of Ob, Gulf of Bengal and the Arabian Sea, and EPIA2 is equidistant $2514 \pm 7 \mathrm{~km}$ from Gulf of $\mathrm{Ob}$, Gulf of Bengal and Gulf of Bohai 
(China). EPIA1 and EPIA2 are 435 and $156 \mathrm{~km}$ far respectively from the location popularly accepted as the EPIA (Figure 4).

The place on Earth that is most distant from land (Pole of Inaccessibility of the Pacific Ocean, or Point Nemo) is at $48^{\circ} 52.6^{\prime} \mathrm{S}, 123^{\circ} 23.6^{\prime} \mathrm{W}, 2690 \pm 2 \mathrm{~km}$ far from the coasts of Motu Nui (Easter Island), Maher Island (Anctartica), and Ducie Island (Pitcairn Islands). PIA's calculated for other continental masses with the same technique are listed in Table 1.

\section{References}

Bonner, W. N. (1987) Antarctic science and conservation-the historical background. Environment International, 13 , pp. $19-25$.

Cable, M. \& French, F. (1944) The Gobi Desert (New York: Macmillan).

Crane, R. \& Crane, N. (1987) Journey To The Centre Of The Earth (London: Bantam Press).

Lambert, G., Ardouin, B., Brichet, E. \& Lorius, C. (1971) Balance of ${ }^{90} \mathrm{Sr}$ over Antarctica: existence of a protected area, Earth and Planetary Science Letters, 11, pp. 317-323.

Petrov, V. P. (1959) Soviet expeditions in Antarctica, The Professional Geographer, 9, pp. 6- 10.

Ramseier, R. O. (1966) Role of sintering in snow construction, Journal of Terramechanics, 3, pp. 41 - 50.

Stefansson, V. (1920) The region of maximum inaccessibility in the Arctic, Geographical Review, 10, pp. $167-172$.

Wessel, P. \& Smith, W. H. F. (1996) A global self-consistent, hierarchical, high-resolution shoreline database, Journal of Geophysical Research, 101, B4, 8741-8743. 